\title{
Treatment with sodium (S)-2-hydroxyglutarate prevents liver injury in an ischemia-reperfusion model in female Wistar rats
}

\author{
Eduardo Cienfuegos-Pecina ${ }^{1,2}$, Diana P Moreno-Peña ${ }^{1}$, Liliana Torres-González ${ }^{1}$, Diana Raquel Rodríguez- \\ Rodríguez ${ }^{1}$, Diana Garza-Villarreal ${ }^{1}$, Oscar H Mendoza-Hernández ${ }^{1}$, Raul Alejandro Flores-Cantú ${ }^{1}$, Brenda \\ Alejandra Samaniego Sáenz ${ }^{1}$, Gabriela Alarcon-Galvan ${ }^{3}$, Linda E Muñoz-Espinosa ${ }^{1}$, Tannya R Ibarra-Rivera ${ }^{4}$, Alma \\ L Saucedo $^{4}$, Paula Cordero-Pérez ${ }^{\text {Corresp. } 1}$ \\ ${ }^{1}$ Liver Unit, Department of Internal Medicine, University Hospital "Dr. José E. González", Universidad Autónoma de Nuevo León, Monterrey, Nuevo León, \\ Mexico \\ 2 Blood Bank, Department of Clinical Pathology, University Hospital "Dr. José E. González", Universidad Autónoma de Nuevo León, Monterrey, Nuevo León, \\ Mexico \\ 3 Basic Science Department, School of Medicine, Universidad de Monterrey, Monterrey, Nuevo León, Mexico \\ 4 Department of Analytical Chemistry, School of Medicine, Universidad Autónoma de Nuevo León, Monterrey, Nuevo León, Mexico \\ Corresponding Author: Paula Cordero-Pérez \\ Email address: paula.corderoprz@uanl.edu.mx
}

Background. Ischemia-reperfusion (IR) injury is one of the leading causes of early graft dysfunction in liver transplantation. Techniques such as ischemic preconditioning protect the graft through the activation of the hypoxia-inducible factors, which are downregulated by the EGLN family of prolyl-4hydroxylases, a potential biological target for the development of strategies based on pharmacological preconditioning. For that reason, this study aims to evaluate the effect of the EGLN inhibitor sodium (S)-2-hydroxyglutarate [(S)-2HG] on liver IR injury in Wistar rats.

Methods. Twenty-eight female Wistar rats were divided into the following groups: sham $(\mathrm{SH}, \mathrm{n}=7)$, non-toxicity (HGTox, $\mathrm{n}=7,25 \mathrm{mg} / \mathrm{kg}$ of $(S)-2 \mathrm{HG}$, twice per day for two days), IR ( $\mathrm{n}=7$, total liver ischemia: 20 minutes, reperfusion: 60 minutes), and (S)-2HG +IR (HGIR, $n=7,25 \mathrm{mg} / \mathrm{kg}$ of (S)-2HG, twice per day for two days, total liver ischemia as the IR group). Serum ALT, AST, LDH, ALP, glucose, and total bilirubin were assessed. The concentrations of IL-1 $\beta, I L-6, T N F$, malondialdehyde, SOD, and glutathione peroxidase were measured in liver tissue, as well as the expression of Hmox1, Vegfa, and Pdk1, determined by RT-qPCR. Sections of liver tissue were evaluated histologically, assessing the severity of necrosis, sinusoidal congestion, and cytoplasmatic vacuolization.

Results. The administration of (S)-2HG did not cause any alteration in the assessed biomarkers compared to SH. Preconditioning with (S)-2HG significantly ameliorated IR injury in the HGIR group, decreasing the serum activities of ALT, AST, and LDH, and the tissue concentrations of IL-1 $\beta$ and IL- 6 compared to the IR group. IR injury decreased serum glucose compared to SH. There were no differences in the other biomarkers assessed. The treatment with (S)-2HG tended to decrease the severity of hepatocyte necrosis and sinusoidal congestion compared to the IR group. The administration of (S)-2HG did not affect the expression of Hmoxl but decreased the expression of both Vegfa and Pdk1 compared to the SH group, suggesting that the HIF-1 pathway is not involved in its mechanism of hepatoprotection. In conclusion, (S)-2HG showed a hepatoprotective effect, decreasing the levels of liver injury and inflammation biomarkers, without evidence of the involvement of the HIF-1 pathway. No hepatotoxic effect was observed at the tested dose. 


\section{Treatment with sodium (S)-2-hydroxyglutarate}

2 prevents liver injury in an ischemia-reperfusion model

3 in female Wistar rats

4

Eduardo Cienfuegos-Pecina ${ }^{1,2}$, Diana P. Moreno-Peña ${ }^{1}$, Liliana Torres-González ${ }^{1}$, Diana R. Rodríguez-Rodríguez ${ }^{1}$, Diana Garza-Villarreal ${ }^{1}$, Oscar H. Mendoza-Hernández ${ }^{1}$, Raúl A. Flores-

7 Cantú ${ }^{1}$, Brenda A. Samaniego-Sáenz ${ }^{1}$, Gabriela Alarcon-Galvan ${ }^{3}$, Linda E. Muñoz-Espinosa ${ }^{1}$,

8 Tannya R. Ibarra-Rivera ${ }^{4}$, Alma L. Saucedo ${ }^{4}$, Paula Cordero-Pérez ${ }^{1}$.

${ }^{1}$ Universidad Autónoma de Nuevo León. Liver Unit, Department of Internal Medicine, University Hospital “Dr. José E. González”, Monterrey, Nuevo León, Mexico.

2 Universidad Autónoma de Nuevo León. Blood Bank, Department of Clinical Pathology, University Hospital “Dr. José E. González”, Monterrey, Nuevo León, Mexico. León, Mexico

Corresponding Author:

Av. Gonzalitos \#235 Col. Mitras Centro, Monterrey, Nuevo León, 64460, Mexico

Email address: paula.corderoprz@uanl.edu.mx

\section{Abstract}

Background. Ischemia-reperfusion (IR) injury is one of the leading causes of early graft dysfunction in liver transplantation. Techniques such as ischemic preconditioning protect the graft through the activation of the hypoxia-inducible factors, which are downregulated by the EGLN family of prolyl-4-hydroxylases, a potential biological target for the development of strategies based on pharmacological preconditioning. For that reason, this study aims to evaluate the effect of the EGLN inhibitor sodium $(S)$-2-hydroxyglutarate $[(S)$-2HG] on liver IR injury in Wistar rats.

Methods. Twenty-eight female Wistar rats were divided into the following groups: sham (SH, $\mathrm{n}$ =7), non-toxicity (HGTox, $\mathrm{n}=7,25 \mathrm{mg} / \mathrm{kg}$ of $(S)-2 \mathrm{HG}$, twice per day for two days), IR ( $\mathrm{n}=7$, total liver ischemia: 20 minutes, reperfusion: 60 minutes), and $(S)-2 \mathrm{HG}+\mathrm{IR}$ (HGIR, $\mathrm{n}=7,25$ $\mathrm{mg} / \mathrm{kg}$ of $(S)-2 \mathrm{HG}$, twice per day for two days, total liver ischemia as the IR group). Serum ALT, AST, LDH, ALP, glucose, and total bilirubin were assessed. The concentrations of IL-1 $\beta$, IL-6, TNF, malondialdehyde, SOD, and glutathione peroxidase were measured in liver tissue, as well as the expression of Hmox 1, Vegfa, and Pdk1, determined by RT-qPCR. Sections of liver tissue 
40 were evaluated histologically, assessing the severity of necrosis, sinusoidal congestion, and

41 cytoplasmatic vacuolization.

42

43

44

45

46

47

48

49

50

51

52

53

54

55

56

57

58

59

60

61

62

63

64

65

66

67

68

69

70

71

72

73

74

75

76

77

78

79

Results. The administration of $(S)-2 \mathrm{HG}$ did not cause any alteration in the assessed biomarkers compared to SH. Preconditioning with $(S)$-2HG significantly ameliorated IR injury in the HGIR group, decreasing the serum activities of ALT, AST, and LDH, and the tissue concentrations of IL-1 $\beta$ and IL-6 compared to the IR group. IR injury decreased serum glucose compared to SH. There were no differences in the other biomarkers assessed. The treatment with $(S)-2 \mathrm{HG}$ tended to decrease the severity of hepatocyte necrosis and sinusoidal congestion compared to the IR group. The administration of $(S)-2 \mathrm{HG}$ did not affect the expression of Hmox 1 but decreased the expression of both Vegfa and Pdkl compared to the SH group, suggesting that the HIF-1 pathway is not involved in its mechanism of hepatoprotection. In conclusion, $(S)-2 \mathrm{HG}$ showed a hepatoprotective effect, decreasing the levels of liver injury and inflammation biomarkers, without evidence of the involvement of the HIF-1 pathway. No hepatotoxic effect was observed at the tested dose.

\section{Introduction}

Orthotopic liver transplantation is the definitive therapy for either end-stage chronic liver disease or severe acute liver failure (Bachir et al. 2012). In Mexico, by the first half of 2020, 317 patients were on a waiting list for liver transplantation and three patients were waiting for combined liver-kidney transplantation. During the same period, only 39 liver transplantations and one combined liver-kidney transplantation were performed in the country (CENATRA 2020).

Despite the improvements in the methodologies of HLA-typification and the immunosuppression strategies, there is still a significant incidence of early graft dysfunction, which is defined by a spectrum of clinical signs that end in acute graft rejection and the need for a retransplant (Briceño \& Ciria 2010). The leading cause of early graft dysfunction is the ischemia-reperfusion (IR) injury; a process that occurs when blood flow to the organ is impaired, causing long-time ischemia, and then it is suddenly restored, reperfusing the tissue with oxygenated blood.

Paradoxically, the oxygen influx enhances the damage mechanisms triggered by hypoxia (Salvadori et al. 2015).

IR injury is a complex process, involving a network of damage mechanisms triggered by hypoxia. When intracellular $\mathrm{O}_{2}$ concentrations plunge, the electron transport chain stops, and the anaerobic glycolysis becomes the main source of ATP for the cell (Dorweiler et al. 2007). Meanwhile, as ATP is depleted, the concentration of ADP increases. ADP is metabolized to hypoxanthine, and its degradation is mediated by the xanthine dehydrogenase, an NAD ${ }^{+} / \mathrm{NADH}$ oxidoreductase which activity is impaired during the ischemic period, increasing the hypoxanthine concentration by 10-fold after 2 hours of ischemia (Schoenberg et al. 1985). When the tissue is suddenly reperfused with oxygenated blood, the oxidative environment favors the oxidation of several cysteine residues in the enzyme xanthine dehydrogenase, causing a 
80

81

82

83

84

85

86

87

88

89

90

91

92

93

94

95

96

97

98

99

100

101

102

103

104

105

106

107

108

109

110

111

112

113

114

115

116

117

118

119

conformational change that changes the activity of the enzyme to an oxidase (Nishino et al. 2005), producing, during the reperfusion, an oxidative burst that is usually lethal to the cells. The fact that reperfusion triggers most of the injury, instead of preventing it, is known as the paradox of IR (Salvadori et al. 2015).

A diversity of strategies have been developed to ameliorate the IR injury, with a particular emphasis on techniques such as the ischemic preconditioning (IPC) (Murry et al. 1986) and the remote ischemic preconditioning (RIPC) (Przyklenk et al. 1993), which consist in short and intermittent periods of ischemia, either in the target organ or in distal organs. It is known that the primary protective mechanism involved with these techniques is the hypoxia-inducible factor (HIF) pathway (Albrecht et al. 2013).

HIFs are transcription factors acting as the primary regulators of oxygen homeostasis. These are heterodimers, conformed by an $\alpha$ subunit, oxygen-dependent, and a $\beta$ subunit constitutively expressed (Semenza 2014). During normoxia, the $\alpha$ subunit is hydroxylated by the EGLN family of prolyl-4-hydroxylases, which are oxygen and $\alpha$-ketoglutarate dependent dioxygenases, and act as the primary oxygen sensors in the cell. After hydroxylation, $\alpha$ subunits are ubiquitinated by the von Hippel-Lindau E3 ubiquitin ligase and degraded in the proteasome. On the other hand, during hypoxia, EGLN hydroxylases are inactive, and the $\alpha$ subunits get stabilized, translocated to the nucleus, and dimerized with $\beta$-subunits, favoring the transcription of their target genes (Dengler et al. 2014). For that reason, this metabolic pathway is a potential therapeutic target for the development of pharmacologic preconditioners.

The 2-hydroxyglutaric acid is an inhibitor of the EGLN hydroxylases. Its $(R)$ enantiomer was the first oncometabolite described in the literature, found in tumors with high resistance to hypoxia, usually harboring a mutated isocitrate dehydrogenase 1 (Dang et al. 2009). On the other hand, its $(S)$ enantiomer is naturally produced in vivo as a product of non-specific reactions of several enzymes, such as the malate dehydrogenase or the lactate dehydrogenase A (Du \& Hu 2021; Intlekofer et al. 2017). The (S)-2-hydroxyglutarate $[(S)-2 \mathrm{HG}]$ has a higher inhibitory effect against EGLN-1 than against EGLN-2 or 3 (Koivunen et al. 2012), and a previous report of our research group showed that the oral administration of its disodium salt has a nephroprotective effect against IR injury in Wistar rats, suggesting the involvement of the HIF-1 pathway in its mechanism (Cienfuegos-Pecina et al. 2020). Given the pharmacologic potential of this compound, we aimed to evaluate whether the administration of (S)-2HG has a hepatoprotective effect against IR injury in Wistar rats.

\section{Materials \& Methods} Synthesis of $(S)$-2HG (S)-2HG was synthesized using a two-step methodology from L-glutamic acid, by using the optimized synthetic route reported by our laboratory (Cienfuegos-Pecina et al. 2020). Briefly, L- 
121

122

123

124

125

126

127

128

129

130

131

132

133

134

135

136

137

138

139

140

141

142

143

144

145

146

147

148

149

150

151

152

153

154

155

156

157

158
120 glutamic acid was subjected to a diazotization reaction in the presence of $\mathrm{NaNO}_{2}$ and $\mathrm{H}_{2} \mathrm{SO}_{4}$ for
12124 hours. The reaction was stopped with $\mathrm{NaCl}$ and extracted three times with ethyl acetate, obtaining the 5-oxotetrahydrofuran-2-carboxylic acid, which was purified by column chromatography, using silica as the stationary phase and ethyl acetate as the mobile phase. This compound was hydrolyzed with $\mathrm{NaOH}, \mathrm{pH} 10$ for two hours, obtaining $(S)$-2HG, which was precipitated with anhydrous methanol.

The identity of the synthesis product was confirmed by nuclear magnetic resonance (NMR) spectroscopy and polarimetry. NMR data were acquired in a Bruker AVANCE III HD $400 \mathrm{MHz}$ spectrometer (Bruker Corp., Billerica, MA, USA). A $50 \mathrm{mg}$ sample of (S)-2HG was dissolved in double-distilled water and analyzed using sodium 3-(trimethylsilyl)propionate-2,2,3,3- $\mathrm{d}_{4}$ (TSP) in $\mathrm{D}_{2} \mathrm{O}$ (Sigma-Aldrich) as an internal standard. The ${ }^{1} \mathrm{H}-\mathrm{NMR}$ and ${ }^{13} \mathrm{C}-\mathrm{NMR}$ spectra were acquired using the noesyprld pulse sequence for water signal suppression and compared with those reported in the literature (Bal \& Gryff-Keller 2002; Cienfuegos-Pecina et al. 2020).

The specific optical rotation $\left([\alpha]_{\mathrm{D}}{ }^{20^{\circ} \mathrm{C}}\right)$ of the synthetic $(S)-2 \mathrm{HG}$ was measured in a PerkinElmer 341 Polarimeter (PerkinElmer, Waltham, MA, USA). Data were compared with previous reports in the literature (Cienfuegos-Pecina et al. 2020; Ritthausen 1872).

\section{Animals}

Twenty-eight healthy female Wistar rats, weighing $238 \pm 18$ g, were used. Every single animal was considered an experimental unit. Rats were bred in-house, and they were kept under standard conditions of light and temperature $\left(24 \pm 3^{\circ} \mathrm{C}, 12\right.$ hours light-dark cycles), with access to commercial rat pellets (Nutrimix de México, Mexico) and water ad libitum. The animals were not genetically engineered, and no previous procedures were performed on the animals before the experiments. All the procedures were performed according to the specifications of the Mexican Official Norm NOM-062-ZOO-1999. This project was submitted to the Ethics and Research Committee of the School of Medicine, Universidad Autónoma de Nuevo León, and approved with the register number HI19-00002.

\section{Experimental design}

The sample size was decided based on the result of an a priori calculation using Equation 1.

$$
n=\frac{(Z \alpha+Z \beta)^{2}\left(\sigma_{1}^{2}+\sigma_{2}^{2}\right)}{\left(\mu_{1}-\mu_{2}\right)^{2}}
$$

Equation 1. Estimation of the sample size for comparison of means. $Z \alpha=Z$-value for $\alpha$; $Z \beta=Z$ value for $\beta ; \sigma_{1}=$ expected standard deviation of group $1 ; \sigma_{2}=$ expected standard deviation of group $2 ; \mu_{1}=$ expected mean of group $1 ; \mu_{2}=$ expected mean of group 2. 
159

160

161

162

163

164

165

166

167

168

169

170

171

172

173

174

175

176

177

178

179

180

181

182

183

184

185

186

187

188

189

190

191

192

193

194

195

196

197

198

As a reference, we considered a previously reported serum activity of ALT of $494 \pm 84 \mathrm{U} / \mathrm{L}$ for rats subjected to the same IR-injury-induction protocol we used (Jiménez Pérez et al. 2016). We calculated the sample size expecting a $40 \%$ decreasing of the serum ALT activity after the treatment (with no change in the standard deviation) and considered a two-tail statistical significance $(\alpha)$ of 0.01 and a statistical power (1- $\beta$ ) of $95 \%$, obtaining a total of 7 rats per group.

Rats were paired with a random number sequence obtained in R v. 4.01. The randomized animals were assigned to the following groups:

- Sham group (SH), $\mathrm{n}=7$ : Rats were treated with double distilled water, p.o., twice per day, for two days. Then they were undergone to laparotomy with exposure of the liver hilum, without inducing IR injury. After 1 hour and 20 minutes, rats were sacrificed by exsanguination, obtaining blood and tissue samples.

- Nontoxicity group (HGTox), $\mathrm{n}=7$ : Rats were treated with double-distilled-waterdissolved $(S)-2 \mathrm{HG}$, at a dose of $25 \mathrm{mg} / \mathrm{kg}$, in the same way as the $\mathrm{SH}$ group. After treatment, they underwent the same procedure as the SH group. A final $n$ of 6 was considered for the data analysis since one of the rats suddenly died after the anesthesia was administered.

- IR group (IR), $\mathrm{n}=7$ : Rats were treated in the same way as the SH group. Then they underwent laparotomy with an exposition of the liver hilum and induction of IR injury (20 minutes of ischemia, one hour of reperfusion).

- (S)-2HG + IR group (HGIR), $\mathrm{n}=7$ : A dose of $25 \mathrm{mg} / \mathrm{kg}$ of $(S)-2 \mathrm{HG}$, was administered to the rats in the same way as the HGTox group. Then, they underwent the same procedure as the IR group.

To minimize potential confounders, all rats were housed in the same room during the experiments, under the same conditions of light and temperature. In each surgery, an equal number of rats from each group underwent the surgical procedure. During the analysis of the biological samples, all the involved were blinded to the identity of the samples, except those who then performed the statistical analysis (Eduardo Cienfuegos-Pecina and Paula Cordero-Pérez).

\section{Induction of liver injury}

Ischemic liver injury was induced following the procedure reported by Jiménez-Pérez et al. (Jiménez Pérez et al. 2016). Rats were anesthetized with $100 \mathrm{mg} / \mathrm{kg}$ of ketamine (Anesket, PiSA Agropecuaria, S.A. de CV, Mexico), and $10 \mathrm{mg} / \mathrm{kg}$ of xylazine (Sedaject, Vedilab S.A. de CV, Mexico), i. p. After asepsis, an incision along the midline was performed, exposing the hepatic hilum, which was then occluded by using an atraumatic vascular clamp (Pringle maneuver) for 20 minutes. Following the ischemia, the clamp was withdrawn, and the rats were kept under general anesthesia for a reperfusion time of 1 hour, after which rats were sacrificed by exsanguination by a puncture in the aorta. Criteria for early euthanasia was the failure of the anesthesia during the surgery, however, none of the animals needed the use of this protocol.

Peer) reviewing PDF | (2021:05:61367:2:0:NEW 9 Oct 2021) 
199 Blood samples were centrifuged at $2000 \mathrm{~g}$ for 12 minutes, then the serum was separated. The 200 liver was resected, weighed, and samples of tissue were obtained and frozen at $-80{ }^{\circ} \mathrm{C}$ until 201 analysis.

202

\section{Biochemical markers, oxidative stress biomarkers, and proinflammatory cytokines}

205

206

207

208

209

210

211

212

213

214

215

216

217

218

219

220

221

222

223

224

225

226

227

228

229

230

231

232

233

234

235

236

237

To assess the magnitude of the induced liver injury, the serum activities of alanine aminotransferase (ALT), aspartate aminotransferase (AST), lactate dehydrogenase (LDH), and alkaline phosphatase (ALP), and the serum concentrations of total bilirubin and glucose were measured. The biochemical determinations were performed in an ILab Aries analyzer (Instrumentation Laboratory, SpA, Milan, Italy), using kinetic and end-point UV-Visible spectrophotometric methodologies.

Malondialdehyde (MDA) is one of the main products of arachidonic acid peroxidation, and it is a commonly used biomarker to assess oxidative stress (Ayala et al. 2014), alongside the activities of superoxide dismutase (SOD) and glutathione peroxidase (GPx). Since one of the key mechanisms involved in IR injury is the oxidative burst produced by the sudden activation of xanthine oxidase, we compared the tissue levels of MDA, SOD, and GPx among the study groups. To measure the concentration of MDA in liver tissue, $200 \mathrm{mg}$ of liver tissue were mechanically homogenized in $1 \mathrm{~mL}$ of RIPA buffer in an ice bath, and then centrifuged at $1600 \mathrm{~g}$ for 10 minutes at $4^{\circ} \mathrm{C}$. MDA concentration was measured spectrophotometrically in the supernatant, using the thiobarbituric acid colorimetric method with a thiobarbituric acid-reactive substances (TBARS) assay kit (Cayman Chemical Company, Ann Arbor, MI, USA). The product of this reaction was measured spectrophotometrically at a wavelength of $535 \mathrm{~nm}$.

The total tissue activity of SOD was quantified by measuring the inhibition of the reduction of a tetrazolium salt to formazan by reactive oxygen species using the SOD Assay Kit (Cayman Chemical Company). Briefly, $200 \mathrm{mg}$ of liver tissue were mechanically homogenized in $1 \mathrm{~mL}$ of $20 \mathrm{mM}$ HEPES buffer, $\mathrm{pH} 7.2$, containing $1 \mathrm{mM}$ EDTA $210 \mathrm{mM}$ mannitol, and $70 \mathrm{mM}$ sucrose. Homogenization was done in an ice bath. Samples were then centrifuged for 15 minutes at $10,000 \mathrm{~g}$, at $4^{\circ} \mathrm{C}$ and the assay was performed using the supernatant, diluted in the buffer. 96well microplates were read spectrophotometrically at a wavelength of $450 \mathrm{~nm}$ and total SOD activity was determined.

Tissue GPx activity was measured by quantifying the oxidation of NADPH to NADP ${ }^{+}$using a GPx Assay Kit (Cayman Chemical Company). To perform the assay, $200 \mathrm{mg}$ of liver tissue were mechanically homogenized in $1 \mathrm{~mL}$ of $50 \mathrm{mM}$ Tris- $\mathrm{HCl}$ buffer, $\mathrm{pH} 7.5$, containing $5 \mathrm{mM}$ EDTA and $1 \mathrm{mM}$ DTT. Homogenization was performed in an ice bath. Samples were centrifuged at $10.000 \mathrm{~g}$ for 15 minutes at $4^{\circ} \mathrm{C}$, and the supernatants were separated. The supernatants were diluted in the sample buffer provided by the manufacturer before the GPx determination. GPx

Peer) reviewing PDF | (2021:05:61367:2:0:NEW 9 Oct 2021) 
238

239

240

241

242

243

244

245

246

247

248

249

250

251

252

253

254

255

256

257

258

259

260

261

262

263

264

265

266

267

268

269

270

271

272

273

274

275

276

277

activity was quantified by a UV kinetic method, measuring the change in the absorbance at a wavelength of $340 \mathrm{~nm}$.

To assess the inflammatory response after the induction of IR injury, we measured the tissue concentrations of the proinflammatory cytokines interleukin $1 \beta$ (IL-1 $\beta$ ), interleukin 6 (IL-6), and tumor necrosis factor (TNF) using a commercial sandwich enzyme-linked immunosorbent assay (ELISA) (R\&D Systems, Minneapolis, MN, USA). The same samples from the GPx determination were used, undiluted. ELISA protocols were performed following the manufacturer's instructions. Cytokine concentrations were determined spectrophotometrically, at a wavelength of $450 \mathrm{~nm}$.

All measurements in tissue were normalized to the protein concentration in the homogenates, measured using Bradford's method. Bradford's reagent was prepared as previously reported in the literature (Kruger 2009). MDA concentration is reported as $\mathrm{mmol} / \mathrm{mg}$ of protein, SOD activity is reported as IU/mg of protein, GPx activity is reported as nmol/min $/ \mathrm{mg}$ of protein, and proinflammatory cytokines are reported as $\mathrm{pg} / \mathrm{mg}$ of protein.

\section{Histological evaluation}

Samples of liver tissue were fixed in phosphate-buffered $10 \%$ formalin solution $\mathrm{pH} 7.4$ and then embedded in paraffin blocks, which were cut using a microtome at a thickness of $4 \mu \mathrm{m}$. The tissue sections were deparaffinized and processed using the standard histological technique. Hematoxylin-eosin (H\&E) stained sections were blindly evaluated under the microscope, assessing the severity of necrosis, cytoplasmic vacuolization, and sinusoidal congestion by using the damage scale reported by Susuki et al. (1993): $0=$ no evident injury; $1=$ single-cell necrosis, minimal congestion or vacuolization; $2=$ necrosis $>30 \%$, mild congestion or vacuolization; $3=$ necrosis $>60 \%$, moderate congestion or vacuolization; and $4=$ necrosis $>60 \%$, severe congestion or vacuolization.

\section{Quantitative RT-PCR}

We used RT-qPCR to measure the expression of Hmoxl, Vegfa, and Pdkl, the genes coding for heme-oxygenase 1, vascular endothelial growth factor A, and pyruvate dehydrogenase kinase 1, whose expression is directly regulated through the HIF-1 pathway (Bernhardt et al. 2009; Bujaldon et al. 2019; Forsythe et al. 1996; Zhang et al. 2018). We performed a total RNA extraction from $100 \mathrm{mg}$ of liver tissue using TRIzol reagent (Invitrogen, Thermo Fisher Scientific, Carlsbad, CA, USA) according to the manufacturer's specifications. The RNA was quantified using a Microdrop Multiskan GO (Thermo Fisher Scientific, Carlsbad, CA, USA) and stored at $-80^{\circ} \mathrm{C}$ until analysis.

We performed all the RT-qPCRs using the GoTaq 1-Step kit (Promega Corporation, Madison, WI, USA). The gene coding for $\beta$-actin $(A c t b)$ was used as the housekeeping gene. The following 
278 primers were used: Hmoxl forward 5'-GCCTGCTAGCCTGGTTCAAGA-3', Hmoxl reverse 5'279 GAGTGTGAGGACCCATCGCA-3', Vegfa forward: 5'-CCGTCCTGTGTGCCCCTAAT-3', 280 Vegfa reverse: 5'-AAACAAATGCTTTCTCCGCT-3', Pdkl forward: 5'281 GATTGCCCATATCACGCCTCT-3', Pdk1 reverse: 5'-CTCGTGGTTGGTTCTGTAATGC-3', 282 Actb forward 5'-CCCTGGCTCCTAGCACCAT-3', and Actb reverse 5'-

283 GATAGAGCCACCAATCCACACA-3'. We performed every reaction according to the

284

285

286

287

288

289

290

291

292

293

294

295

296

297

298

299

300

301

302

303

304

305

306

307

308

309

310

311

312

313

314

315

316

317 manufacturer's specifications, using $200 \mathrm{ng}$ of RNA for each reaction and the primers at a concentration of $100 \mathrm{nM}$, to complete a final volume of $20 \mu \mathrm{L}$. The following reaction conditions were used: one cycle of reverse transcription at $37^{\circ} \mathrm{C}$ for 15 minutes, one cycle of reverse transcription inactivation and Go Taq DNA Polymerase activation at $95^{\circ} \mathrm{C}$ for 10 minutes, and 40 cycles of denaturation at $95^{\circ} \mathrm{C}$ for 10 seconds and annealing/extension at $60^{\circ} \mathrm{C}$ for 30 seconds. Fold changes of gene expression from the SH group were calculated using the $2^{-\Delta \Delta \mathrm{Ct}}$ method.

\section{Statistical analysis}

Data were analyzed using a Shapiro-Wilk normality test, followed by either a one-way ANOVA test with a Tukey post hoc test or a Kruskal-Wallis test with a Dunn post hoc test. For the gene expression assessment, the $-\Delta \Delta \mathrm{C}_{\mathrm{T}}$ values were analyzed. All the statistical analyses were performed in R v. 4.0.1, using the packages tidyverse, cowplot, and PMCMRplus. The full datasets are supplied in Supplementary Files 1-4, while the code used for the statistical analysis is supplied in Supplementary File 5. The results are expressed as mean \pm standard deviation or median (interquartile range), depending on their distribution. Differences between groups are considered significant at $p<0.05$.

\section{Results}

\section{(S)-2HG was successfully synthesized from L-glutamic acid}

(S)-2HG was produced in a $29.78 \%$ yield after alkaline hydrolysis, and it was obtained as a beige powder, highly hygroscopic, and soluble in water but insoluble in organic solvents such as methanol, ethanol, acetone, and ethyl acetate. The ${ }^{1} \mathrm{H}-\mathrm{NMR}$ spectrum showed the following signals: $1.82 \mathrm{ppm}(1 \mathrm{H}, \mathrm{m}) ; 1.96 \mathrm{ppm}(1 \mathrm{H}, \mathrm{m}) ; 2.22 \mathrm{ppm}(2 \mathrm{H}, \mathrm{m})$, and $4.00 \mathrm{ppm}\left(1 \mathrm{H}, \mathrm{dd}, J^{\prime}=7.6\right.$ $\mathrm{Hz}, J^{\prime \prime}=4.0 \mathrm{~Hz}$ ) (Figure $\mathrm{S} 1$ ). In the ${ }^{13} \mathrm{C}-\mathrm{NMR}$ spectrum, the following signals were observed: $33.91,36.38,75.01,184.10$, and $185.71 \mathrm{ppm}$ (Figure S2). Both spectra were consistent with the reported in the literature for this compound (Bal \& Gryff-Keller 2002; Cienfuegos-Pecina et al. 2020). A value of $[\alpha]_{\mathrm{D}^{20}}{ }^{\circ} \mathrm{C}=8.4^{\circ} \mathrm{cm}^{3} \mathrm{~g}^{-1} \mathrm{dm}^{-1}$ was observed, and it was consistent with previously reported data (Cienfuegos-Pecina et al. 2020; Ritthausen 1872).

\section{(S)-2HG is hepatoprotective, but not hepatotoxic at the tested dose}

To evaluate whether $(S)-2 \mathrm{HG}$ produces an acute hepatotoxic effect, we compared the levels of liver injury biomarkers between the SH and HGTox groups. We did not observe a significant difference between these groups in any of the assessed biochemical markers (Figure 1). 
To assess whether $(S)-2 \mathrm{HG}$ had a hepatoprotective effect, we compared the levels of the liver injury biomarkers among the SH, IR, and HGIR groups. Neither the treatment with $(S)-2 \mathrm{HG}$ nor the IR injury induction affected the liver weight of the animals (Figure S3). The induction of IR injury significantly increased the serum activities of ALT, AST, and LDH compared to the SH group, while the treatment with $(S)-2 \mathrm{HG}$ produced a significant decrease in the serum activities of these enzymes compared to the IR group (Figure 1). A significant decrease in serum glucose concentration was observed in both, the IR and HGIR groups compared to the SH group. No significant differences were observed among groups in the serum activity of ALP and the serum concentration of total bilirubin (Figure 1).

328

\section{The experimental model of total liver IR injury did not affect the levels of oxidative stress}

\section{biomarkers in liver tissue}

331

No significant differences were observed in the levels of oxidative stress biomarkers between the

332

333

334

335

336

337

338

339

340

341

342

343

344

345

346

347

348

349

350

351

352

353

354

355

356

357

IR and SH groups (Table 1). Their levels were not affected by the administration of $(S)-2 \mathrm{HG}$ in the HGTox group. We observed a decrease in the tissue activity of GPx in the HGIR group compared with both SH and IR groups (Table 1).

\section{(S)-2HG modulates the concentration of proinflammatory cytokines}

Our model of acute liver injury produced a significant increase in the tissue concentration of IL$1 \beta$ in the IR group compared to the SH group. Treatment with $(S)-2 \mathrm{HG}$ prevented this increase, as we observed a concentration of IL-1 $\beta$ in the HGIR group significantly lower than the concentration in the IR group (Figure 2).

The induction of liver IR injury did not affect the tissue concentrations of IL-6 and TNF, however, a significant decrease in the tissue concentration of these cytokines was observed in the HGIR group, compared with both IR and SH groups (Figure 2). The administration of $(S)-2 \mathrm{HG}$ to the HGTox group did not cause any alteration in the levels of the assessed cytokines compared to the $\mathrm{SH}$ group (Figure 2).

\section{(S)-2HG produced a trend to decrease the severity of the histological liver injury, but it was} not significative

The administration of $(S)-2 \mathrm{HG}$ to the HGTox group did not produce a significant change in the scores of histological liver injury compared to the SH group (Table 2, Figure 3). On the other hand, our model of IR injury induced a significant degree of necrosis and sinusoidal congestion in the IR group compared to the SH group, without producing a significant increase in the degree of cytoplasmic vacuolization (Table 2, Figure 3). The histopathological evaluation of the IR group showed cellular eosinophilia and nuclear hyperchromasia. Cellular necrosis was severe at zone 3 of the liver acinus, with disruption of the central vein endothelial border (Figure 3 ). The administration of $(S)-2 \mathrm{HG}$ tended to decrease the severity of necrosis and sinusoidal congestion 
358

359

360

361

362

363

364

365

366

367

368

369

370

371

372

373

374

375

376

377

378

379

380

381

382

383

384

385

386

387

388

389

390

391

392

393

394

395

396

397

compared to the IR group, although this decrease was not statistically significant (Table 2, Figure 3).

\section{The treatment with $(S)$-2HG decreased the expression of $V e g f a$ and $P d k 1$ in liver tissue, without affecting the expression of $\mathrm{Hmoxl}$}

Contrarily as we expected, the treatment with (S)-2HG did not increase the expression of Hmoxl, $V e g f a$, or Pdkl in liver tissue. The expression of Hmoxl in liver tissue was not affected by the administration of (S)-2HG or by the induction of IR injury (Figure 4). On the other hand, we observed a significant decrease in the expression of both, Vegfa and Pdkl in the rats of the HGTox group compared to the SH group (Figure 4). The induction of IR also decreased the expression of these genes compared to the SH group (Figure 4). These observations suggest that the hepatoprotective effect of (S)-2HG is not mediated by the HIF-1 metabolic axis, since we did not observe the genetic footprint of the HIF-1 $\alpha$ stabilization, indicating the involvement of a different, currently unidentified mechanism.

\section{Discussion}

Liver transplantation is still the definitive therapy for end-stage liver diseases. However, the lack of donors makes every organ invaluable. Hence, a plethora of strategies has been assessed to improve graft survival. Several strategies have been developed to ameliorate IR injury, aiming to stop the damage cascade at several levels. Pretreatment with antioxidant compounds, such as curcumin or plant extracts with free-radical scavenging activity, has been used to decrease the intensity of the oxidative burst during IR injury (Jiménez Pérez et al. 2016; Shen et al. 2007; Torres-González et al. 2018; Yildiz et al. 2015). The use of anti-inflammatory drugs has also been evaluated, aiming to ameliorate the inflammatory response after IR injury, which is the pathogenic mechanism that drives acute graft rejection (Abdel-Gaber et al. 2015). These strategies are aimed to ameliorate the damage that happens during reperfusion. However, only a few have been designed to prevent during the ischemia the cascade of events that lead to the reperfusion injury. Surgical techniques such as IPC and RIPC have been demonstrated to be promising in pre-clinical studies (Abu-Amara et al. 2011), however, the evidence of their effectiveness in clinical studies is controversial (Zapata-Chavira et al. 2017; Zapata-Chavira et al. 2015). The mechanism behind IPC and RIPC is still not completely understood, but it is well known that the HIF-1 pathway plays an essential role in its protective effect (Cai et al. 2013). The stabilization of HIF-1 $\alpha$ through the inhibition of the EGLN family of prolyl-4-hydroxylases has demonstrated a protective effect against IR injury in several tissues (Hill et al. 2008; Vogler et al. 2015). In a previous report of our laboratory, we demonstrated that $(S)-2 \mathrm{HG}$ has a nephroprotective effect against IR injury in Wistar rats (Cienfuegos-Pecina et al. 2020).

Several animal models have been used to study the mechanisms of IR injury in several organs. Studies relying on relatively big animals, such as pigs (Andria et al. 2013) and dogs (Choi et al. 2010) have the advantage of a good similarity to humans, however, these models have been 
398

399

400

401

402

403

404

405

406

407

408

409

410

411

412

413

414

415

416

417

418

419

420

421

422

423

424

425

426

427

428

429

430

431

432

433

434

435

436

437

gradually abandoned due to ethical considerations. Experimental models in rodents, such as mice, are considered attractive, given the availability of genetically modified strains. On the other hand, rat models of IR injury have been well characterized (Jiménez Pérez et al. 2016) and have the advantage of larger anatomical structures, allowing the performance of accurate surgical procedures without the need for microsurgery instruments. In addition, rat models are a good starting point for the screening of compounds with potential hepatoprotective activity. Hence, we decided to perform our study using a well-characterized model of liver IR injury in Wistar rats.

It has been demonstrated that the severity of IR injury is sex-dependent, involving a modulatory effect of the sex hormones. Some studies have shown that female rodents exert a higher resistance to liver IR injury than males, via an estrogen-dependent mechanism (Eckhoff et al. 2002; Harada et al. 2003). Estrogen induces the activity of the endothelial cell isoform of NO synthase (eNOS) through the estrogen receptor- $\alpha$. The mechanism involves either the Aktmediated activation of eNOS or the upregulation in the transcription of its gene (Harada et al. 2003). Since the effect of IR injury is different between females and males, the study of mixed groups is not appropriate. Hence, we choose to assess the effect of our liver IR injury model specifically in female Wistar rats.

In this study, we observed that the pretreatment with $(S)-2 \mathrm{HG}$ at a dose of $25 \mathrm{mg} / \mathrm{kg}$ protects the liver against IR in a protocol of 20 minutes of ischemia and 1 hour of reperfusion, evidenced by a significant decrease in the serum activities of ALT, AST, and LDH compared to the IR group. These three enzymes are the most used biomarkers to assess hepatocellular necrosis in a clinical context because are highly expressed in the hepatocytes (Giannini et al. 2005; Jiménez Pérez et al. 2016). We also observed a decrease in the serum concentrations of glucose in both, the IR and HGIR groups compared to SH. It has been demonstrated that liver ischemia impairs glucose metabolism, affecting the gluconeogenesis pathway and decreasing the serum glucose concentration during the late ischemia and reperfusion (Bailey \& Reinke 2000; Bloechle et al. 1994). There was no significant increase, but a trend, in the serum activity of ALP and the serum concentration of total bilirubin after the induction of IR injury, indicating that IR injury induction affected to a lesser extent the bile ducts than the liver parenchyma. On the other hand, (S)-2HG did not affect the levels of the assessed biochemical markers compared in the HGTox group compared to the SH group, evidencing that the compound has no hepatotoxic effect at the tested dose. These results agree with our previous report, in which no acute hepatotoxic or nephrotoxic effect was observed at a dose of 12.5 and $25 \mathrm{mg} / \mathrm{kg}$ (Cienfuegos-Pecina et al. 2020), however, additional studies assessing the toxicity of $(S)-2 \mathrm{HG}$ at higher doses and after chronic exposure are still needed.

Despite the involvement of oxidative stress in the mechanism of IR injury, we did not observe a significant difference in the assessed oxidative stress biomarkers (MDA, SOD, and GPX) neither in the IR group compared to the SH group, nor in the HGIR group compared to the IR group. It 
438 has been reported in the literature that despite the role of oxidative stress in the process of IR 439 injury, its effect on the three assessed biomarkers is detected only after longer periods of 440 ischemia and reperfusion (Gupta et al. 1997). The characteristics of our model (20 minutes of 441 ischemia and 1 hour of reperfusion) allow us to induce a moderated IR injury, however, the 442 assessed biomarkers were not sensitive enough to detect the oxidative stress associated with IR 443 injury. Even when this model is ideal for the screening of new compounds with hepatoprotective

444

445 446

447 activity, additional experiments must be performed to accurately quantify the effect of the evaluated compounds on the redox balance after the induction of IR injury.

Proinflammatory cytokines play an important role in the physiopathology of IR injury, being involved in the acute rejection of the graft. It has been demonstrated that the intensity of IR injury dictates the magnitude of the inflammatory response, as evidenced by the correlation of the expression of IL-1 $\beta$ and the duration of ischemia and reperfusion (Jiménez-Castro et al. 2019). In this study, we observed that only IL-1 $\beta$ was significantly affected by our model of IR injury. This agrees with a previous report showing that a mild ischemic injury is not enough to induce an increase in the tissue concentration of proinflammatory cytokines during the reperfusion period (Jiménez Pérez et al. 2016). We observed a significant decrease in the tissue concentration of IL-1 $\beta$ in the HGIR group compared to the IR group. This indicates that the amelioration of IR injury by the treatment with $(S)-2 \mathrm{HG}$ is enough to impact the inflammatory response derived from the ischemic insult. Besides, despite our model of IR injury was unable to increase the tissue concentrations of IL- 6 and TNF in the IR group compared to the SH group, we observed a decrease in the levels of these cytokines in the HGIR group.

The induction of IR injury caused a significant disruption of the tissue architecture, evidenced by severe cell necrosis and sinusoidal congestion in zone 3 of the liver acinus. Since zone 3 is the last to be reached by the oxygenated blood coming from the portal triad, it is more prone to be affected after the induction of IR injury (Ali et al. 2015). In our study, our model of mild IR injury produced significant damage in the perivenular zone, without affecting extensively the region around the portal triad. This histopathological finding agrees with the levels of serum ALP and total bilirubin in the IR group, which did not increase significantly compared to the SH group. The administration of $(S)-2 \mathrm{HG}$ to the HGIR group produced a decrease in the severity of both, cell necrosis and sinusoidal congestion. However, this decrease was not statistically significant in the non-parametric Kruskal-Wallis test. A quantitative morphometric analysis of the tissue sections would be helpful in future studies to measure the effect of $(S)-2 \mathrm{HG}$ at the tissue level.

Heme oxygenase 1 is the inducible isoform of heme oxygenase, and it is codified by the gene Hmox1. Its expression is directly regulated by the HIF-1 pathway (Lee et al. 1997), just like the genes codifying for the vascular endothelial growth factor A (Vegfa) (Forsythe et al. 1996) and the pyruvate dehydrogenase kinase 1 ( $P d k 1)$ (Majmundar et al. 2010). Together, these genes are 
478

479

480

481

482

483

484

485

486

487

488

489

490

491

492

493

494

495

496

497

498

499

500

501

502

503

504

505

506

507

508

509

510

511

512

513

514

515

516

517

assessed to detect the footprint of the stabilization of HIF-1 $\alpha$, since this protein is not easily detected directly, mainly due to its instability in normoxic conditions (Wang et al. 2017; Zhang et al. 2018). A previous report demonstrates that the upregulation of Hmoxl by the stabilization of HIF-1 $\alpha$ attenuates postischemic myocardial injury in both, in vitro and in vivo models, with an associated downregulation of the expression of IL-8 (Dawn \& Bolli 2005). We previously observed that the administration of $(S)-2 \mathrm{HG}$ at a dose of $25 \mathrm{mg} / \mathrm{kg}$ induces a 14.15 -fold increase in the expression of Hmox 1 in kidney tissue, with a nephroprotective effect against IR injury (Cienfuegos-Pecina et al. 2020). Surprisingly, in this study, we did not observe any modification in the expression levels of Hmoxl after the administration of $25 \mathrm{mg} / \mathrm{kg}$ of $(S)-2 \mathrm{HG}$. In addition, instead of observing an increase in the expression of Vegfa and Pdkl after the treatment with $(S)$ $2 \mathrm{HG}$, we observed a significant decrease. Also, the induction of IR injury decreased the expression of both genes.

The behavior of Vegfa in the rats subjected to IR injury agrees with a previous report, showing that during the first stage of the IR injury induction the expression of Vegfa is decreased (Bujaldon et al. 2019), however, the decrease of its expression in the HGTox group suggests that the HIF-1 - VEGF axis is not involved in the hepatoprotective effect of (S)-2HG since Vegfa expression is directly upregulated by HIF-1 (Forsythe et al. 1996). This finding is supported by the behavior of $P d k 1$, which also significantly decreased its expression in the HGTox group. Together, these results suggest that $(S)-2 \mathrm{HG}$ exerts its hepatoprotective effect by a different mechanism than the one observed in kidney tissue (Cienfuegos-Pecina et al. 2020). Further studies are needed to identify the metabolic pathways involved.

The increased activity of $(S)-2 \mathrm{HG}$ dehydrogenase in liver tissue may play a major role in its pharmacokinetics. In the liver tissue, the $(S)-2 \mathrm{HG}$ dehydrogenase has an activity more than 4 times higher than in kidney tissue (Jansen \& Wanders 1993). This enzyme catalyzes the oxidation of $(S)-2 \mathrm{HG}$ in a $\mathrm{FAD}^{+}$-dependent mechanism, producing $\alpha$-ketoglutarate (Rzem et al. 2006), which, according to a previous report, exhibits a hepatoprotective effect by regulating the polarization of Kupffer cells from an M1 to an M2 phenotype, decreasing the severity of the IR injury and the expression of IL-6 (Cheng et al. 2019). The hypothesis of an involvement of an $\alpha-$ ketoglutarate-dependant mechanism would agree with our findings since we observed a downregulation of the tissue concentration of IL-6 in the HGIR group. Because neither SOD nor GPx exhibit FAD ${ }^{+}$-dependent mechanisms, an increase in the cellular concentration of $\mathrm{FADH}_{2}$ would not affect these biomarkers. Also, it has been reported that $\alpha$-ketoglutarate inhibits the expression of Vegfa in osteosarcoma cell lines (Kaławaj et al. 2020), which agrees with our observation that Vegfa was downregulated in the rats treated with $(S)-2$ HG. The fact that $\alpha-$ ketoglutarate is the actual substrate of the EGLN hydroxylases could also explain the observed downregulation of $V e g f a$ and $P d k l$ by inactivation (instead of stabilization) of HIF-1 $\alpha$. Additional experiments are needed to elucidate the mechanism of action of $(S)-2 \mathrm{HG}$ against IR injury in liver tissue.

Peer) reviewing PDF | (2021:05:61367:2:0:NEW 9 Oct 2021) 
518

519 The pharmacokinetics of $(S)-2 \mathrm{HG}$ is still not fully understood. Since the disodium salt of $(S)$ -

520

521

522

523

524

525

526

527

528

529

530

531

532

533

534

535

536

537

538

539

540

541

542

543

544

545

546

547

548

549

550

551

552

553

554

555

556

557

558

559

560

$2 \mathrm{HG}$ is highly polar, it is very unlikely that it could permeate through cell membranes. However, it has been reported that $(S)-2 \mathrm{HG}$ undergoes protonation and then cyclization at an acidic $\mathrm{pH}$ (Bal \& Gryff-Keller 2002). This process would form an equilibrium between $(S)-2 \mathrm{HG}$ and its more hydrophilic lactone in the stomach after its administration $p . o$., increasing the absorption and biodisponibility. Further studies with a diversity of derivatives of $(S)-2 \mathrm{HG}$ are needed to give us a better understanding of its pharmacokinetics and to identify analogs with a higher pharmacologic potential.

\section{Conclusions}

(S)-2HG has a hepatoprotective effect against IR injury, which involved the amelioration of liver injury biomarkers and proinflammatory cytokines. The administration of $(S)$-2HG did not induce an acute hepatotoxic effect at the tested dose. The expression of Hmoxl in liver tissue was not affected by the pre-treatment with $(S)-2 \mathrm{HG}$, while the expression of $V e g f a$ and $P d k 1$ was decreased, indicating that the HIF-1 pathway does not play a role in the hepatoprotective effect of $(S)-2 \mathrm{HG}$ and suggesting the involvement of additional pathways in its mechanism of hepatoprotection.

\section{References}

Abdel-Gaber SA, Ibrahim MA, Amin EF, Ibrahim SA, Mohammed RK, and Abdelrahman AM. 2015. Effect of selective versus non-selective cyclooxygenase inhibitors on ischemiareperfusion-induced hepatic injury in rats. Life Sciences 134:42-48. https://doi.org/10.1016/j.lfs.2015.04.025

Abu-Amara M, Yang SY, Quaglia A, Rowley P, Tapuria N, Seifalian AM, Fuller BJ, and Davidson BR. 2011. Effect of remote ischemic preconditioning on liver ischemia/reperfusion injury using a new mouse model. Liver Transplantation 17:70-82. https://doi.org/10.1002/lt.22204

Albrecht M, Zitta K, Bein B, Wennemuth G, Broch O, Renner J, Schuett T, Lauer F, Maahs D, Hummitzsch L, Cremer J, Zacharowski K, and Meybohm P. 2013. Remote ischemic preconditioning regulates HIF-1alpha levels, apoptosis and inflammation in heart tissue of cardiosurgical patients: a pilot experimental study. Basic Research in Cardiology 108:314. https://doi.org/10.1007/s00395-012-0314-0

Ali JM, Davies SE, Brais RJ, Randle LV, Klinck JR, Allison MED, Chen Y, Pasea L, Harper SFJ, and Pettigrew GJ. 2015. Analysis of ischemia/reperfusion injury in time-zero biopsies predicts liver allograft outcomes. Liver Transplantation 21:487-499. https://doi.org/10.1002/lt.24072

Andria B, Bracco A, Attanasio C, Castaldo S, Cerrito MG, Cozzolino S, Di Napoli D, Giovannoni R, Mancini A, Musumeci A, Mezza E, Nasti M, Scuderi V, Staibano S, 
561

562

563

564

565

566

567

568

569

570

571

572

573

574

575

576

577

578

579

580

581

582

583

584

585

586

587

588

589

590

591

592

593

594

595

596

597

598

599

600

601

602

603

604

605

606
Lavitrano M, Otterbein LE, and Calise F. 2013. Biliverdin Protects against Liver Ischemia Reperfusion Injury in Swine. PLOS ONE 8:e69972. https://doi.org/10.1371/journal.pone.0069972

Ayala A, Muñoz MF, and Argüelles S. 2014. Lipid Peroxidation: Production, Metabolism, and Signaling Mechanisms of Malondialdehyde and 4-Hydroxy-2-Nonenal. Oxidative Medicine and Cellular Longevity 2014:31. https://doi.org/10.1155/2014/360438

Bachir NM, Larson AM, and Palmer BF. 2012. Adult Liver Transplantation in the United States. The American Journal of the Medical Sciences 343:462-469. https://doi.org/10.1097/MAJ.0b013e3182308b66

Bailey SM, and Reinke LA. 2000. Effect of low flow ischemia-reperfusion injury on liver function. Life Sciences 66:1033-1044. https://doi.org/10.1016/S0024-3205(99)00668-2

Bal D, and Gryff-Keller A. 2002. 1H and 13C NMR study of 2-hydroxyglutaric acid and its lactone. Magnetic Resonance in Chemistry 40:533-536. https://doi.org/10.1002/mrc.1053

Bernhardt WM, Gottmann U, Doyon F, Buchholz B, Campean V, Schödel J, Reisenbuechler A, Klaus S, Arend M, Flippin L, Willam C, Wiesener MS, Yard B, Warnecke C, and Eckardt K-U. 2009. Donor treatment with a PHD-inhibitor activating HIFs prevents graft injury and prolongs survival in an allogenic kidney transplant model. Proceedings of the National Academy of Sciences 106:21276-21281. https://doi.org/10.1073/pnas.0903978106

Bloechle C, Kusterer K, Konrad T, Hosch SB, Izbicki JR, Knoefel WT, Broelsch CE, and Usadel KH. 1994. Rat Liver Injury Induced by Hypoxic Ischemia and Reperfusion: Protective Action by Somatostatins is Independent from Changes in Glucose Metabolism. Hormone and Metabolic Research 26:270-275. https://doi.org/10.1055/s-2007-1001682

Briceño J, and Ciria R. 2010. Early Graft Dysfunction After Liver Transplantation. Transplantation Proceedings 42:631-633. https://doi.org/10.1016/j.transproceed.2010.02.004

Bujaldon E, Cornide-Petronio ME, Gulfo J, Rotondo F, Ávalos de León C, Negrete-Sánchez E, Gracia-Sancho J, Novials A, Jiménez-Castro MB, and Peralta Uroz C. 2019. Relevance of VEGFA in rat livers subjected to partial hepatectomy under ischemia-reperfusion. Journal of Molecular Medicine 97:1299-1314. https://doi.org/10.1007/s00109-019$\underline{01811-y}$

Cai Z, Luo W, Zhan H, and Semenza GL. 2013. Hypoxia-inducible factor 1 is required for remote ischemic preconditioning of the heart. Proceedings of the National Academy of Sciences 110:17462-17467. https://doi.org/10.1073/pnas.1317158110

CENATRA. 2020. Boletín Estadístico Informativo Centro Nacional de Trasplantes. México: Centro Nacional de Trasplantes.

Peer) reviewing PDF | (2021:05:61367:2:0:NEW 9 Oct 2021) 
607 Cheng M-x, Cao D, Chen Y, Li J-z, Tu B, and Gong J-p. 2019. $\alpha$-ketoglutarate attenuates 608 ischemia-reperfusion injury of liver graft in rats. Biomedicine \& Pharmacotherapy

609

610

611

612

613

614

615

616

617

618

619

620

621

622

623

624

625

626

627

628

629

630

631

632

633

634

635

636

637

638

639

640

641

642

643

644

645

646

647

648

649

650

651

652
111:1141-1146. https://doi.org/10.1016/i.biopha.2018.12.149

Choi JM, Park KM, Kim SH, Hwang DW, Chon SH, Lee JH, Lee SY, and Lee YJ. 2010. Effect of Necrosis Modulator Necrox-7 on Hepatic Ischemia-Reperfusion Injury in Beagle Dogs. Transplantation Proceedings 42:3414-3421. https://doi.org/10.1016/j.transproceed.2010.08.050

Cienfuegos-Pecina E, Ibarra-Rivera TR, Saucedo AL, Ramírez-Martínez LA, Esquivel-Figueroa D, Domínguez-Vázquez I, Alcántara-Solano KJ, Moreno-Peña DP, Alarcon-Galvan G, Rodríguez-Rodríguez DR, Torres-González L, Muñoz-Espinosa LE, Pérez-Rodríguez E, and Cordero-Pérez P. 2020. Effect of sodium (S)-2-hydroxyglutarate in male, and succinic acid in female Wistar rats against renal ischemia-reperfusion injury, suggesting a role of the HIF-1 pathway. PeerJ 8:e9438. https://doi.org/10.7717/peerj.9438

Dang L, White DW, Gross S, Bennett BD, Bittinger MA, Driggers EM, Fantin VR, Jang HG, Jin S, Keenan MC, Marks KM, Prins RM, Ward PS, Yen KE, Liau LM, Rabinowitz JD, Cantley LC, Thompson CB, Vander Heiden MG, and Su SM. 2009. Cancer-associated IDH1 mutations produce 2-hydroxyglutarate. Nature 462:739-744. https://doi.org/10.1038/nature08617

Dawn B, and Bolli R. 2005. HO-1 induction by HIF-1: a new mechanism for delayed cardioprotection? American Journal of Physiology-Heart and Circulatory Physiology 289:H522-H524. https://doi.org/10.1152/ajpheart.00274.2005

Dorweiler B, Pruefer D, Andrasi TB, Maksan SM, Schmiedt W, Neufang A, and Vahl CF. 2007. Ischemia-Reperfusion Injury. European Journal of Trauma and Emergency Surgery 33:600-612. https://doi.org/10.1007/s00068-007-7152-z

$\mathrm{Du} \mathrm{X}$, and $\mathrm{Hu} \mathrm{H} .2021$. The Roles of 2-Hydroxyglutarate. Frontiers in Cell and Developmental Biology 9. https://doi.org/10.3389/fcell.2021.651317

Eckhoff DE, Bilbao G, Frenette L, Thompson JA, and Contreras JL. 2002. 17-Beta-estradiol protects the liver against warm ischemia/reperfusion injury and is associated with increased serum nitric oxide and decreased tumor necrosis factor-alpha. Surgery 132:302309. https://doi.org/10.1067/msy.2002.125718

Forsythe JA, Jiang BH, Iyer NV, Agani F, Leung SW, Koos RD, and Semenza GL. 1996. Activation of vascular endothelial growth factor gene transcription by hypoxia-inducible factor 1. Molecular and Cellular Biology 16:4604-4613. https://doi.org/10.1128/MCB.16.9.4604

Giannini EG, Testa R, and Savarino V. 2005. Liver enzyme alteration: a guide for clinicians. Canadian Medical Association Journal 172:367-379. https://doi.org/10.1503/cmaj.1040752

Peer) reviewing PDF | (2021:05:61367:2:0:NEW 9 Oct 2021) 
653

654

655

656

657

658

659

660

661

662

663

664

665

666

667

668

669

670

671

672

673

674

675

676

677

678

679

680

681

682

683

684

685

686

687

688

689

690

691

692

693

694

695

696

697
Gupta M, Dobashi K, Greene EL, Orak JK, and Singh I. 1997. Studies on hepatic injury and antioxidant enzyme activities in rat subcellular organelles following in vivo ischemia and reperfusion. Molecular and Cellular Biochemistry 176:337-347. https://doi.org/10.1023/A:1006829902442

Harada H, Pavlick KP, Hines IN, Lefer DJ, Hoffman JM, Bharwani S, Wolf RE, and Grisham MB. 2003. Sexual dimorphism in reduced-size liver ischemia and reperfusion injury in mice: Role of endothelial cell nitric oxide synthase. Proceedings of the National Academy of Sciences 100:739-744. https://doi.org/10.1073/pnas.0235680100

Hill P, Shukla D, Tran MGB, Aragones J, Cook HT, Carmeliet P, and Maxwell PH. 2008. Inhibition of Hypoxia Inducible Factor Hydroxylases Protects Against Renal IschemiaReperfusion Injury. Journal of the American Society of Nephrology 19:39-46. https://doi.org/10.1681/asn.2006090998

Intlekofer AM, Wang B, Liu H, Shah H, Carmona-Fontaine C, Rustenburg AS, Salah S, Gunner MR, Chodera JD, Cross JR, and Thompson CB. 2017. L-2-Hydroxyglutarate production arises from noncanonical enzyme function at acidic $\mathrm{pH}$. Nature Chemical Biology 13:494-500. https://doi.org/10.1038/nchembio.2307

Jansen GA, and Wanders RJA. 1993. 1-2-Hydroxyglutarate dehydrogenase: identification of a novel enzyme activity in rat and human liver. Implications for 1-2-hydroxyglutaric acidemia. Biochimica et Biophysica Acta (BBA) - Molecular Basis of Disease 1225:5356. https://doi.org/10.1016/0925-4439(93)90121-G

Jiménez-Castro MB, Cornide-Petronio ME, Gracia-Sancho J, and Peralta C. 2019. Inflammasome-Mediated Inflammation in Liver Ischemia-Reperfusion Injury. Cells 8:1131. https://doi.org/10.3390/cells8101131

Jiménez Pérez JC, Casillas Ramírez A, Torres González L, Muñoz Espinosa LE, Perales Quintana MM, Alarcón Galván G, Zapata Chavira H, de la Garza G, Javier F, and Cámara Lemarroy CR. 2016. Spironolactone effect in hepatic ischemia/reperfusion injury in Wistar rats. Oxidative Medicine and Cellular Longevity 2016. https://doi.org/10.1155/2016/3196431

Kaławaj K, Sławińska-Brych A, Mizerska-Kowalska M, Żurek A, Bojarska-Junak A, KandeferSzerszeń M, and Zdzisińska B. 2020. Alpha Ketoglutarate Exerts In Vitro AntiOsteosarcoma Effects through Inhibition of Cell Proliferation, Induction of Apoptosis via the JNK and Caspase 9-Dependent Mechanism, and Suppression of TGF- $\beta$ and VEGF Production and Metastatic Potential of Cells. International Journal of Molecular Sciences 21. https://doi.org/10.3390/ijms21249406

Koivunen P, Lee S, Duncan CG, Lopez G, Lu G, Ramkissoon S, Losman JA, Joensuu P, Bergmann U, Gross S, Travins J, Weiss S, Looper R, Ligon KL, Verhaak RGW, Yan H,

Peer] reviewing PDF | (2021:05:61367:2:0:NEW 9 Oct 2021) 
698

699

700

701

702

703

704

705

706

707

708

709

710

711

712

713

714

715

716

717

718

719

720

721

722

723

724

725

726

727

728

729

730

731

732

733

734

735

736

737

738

739

740

741

742

743 and Kaelin Jr WG. 2012. Transformation by the (R)-enantiomer of 2-hydroxyglutarate linked to EGLN activation. Nature 483:484-488. https://doi.org/10.1038/nature10898

Kruger NJ. 2009. The Bradford Method For Protein Quantitation. In: Walker JM, ed. The Protein Protocols Handbook. Totowa, NJ: Humana Press, 17-24.

Lee PJ, Jiang B-H, Chin BY, Iyer NV, Alam J, Semenza GL, and Choi AMK. 1997. Hypoxiainducible Factor-1 Mediates Transcriptional Activation of the Heme Oxygenase-1 Gene in Response to Hypoxia. Journal of Biological Chemistry 272:5375-5381. https://doi.org/10.1074/jbc.272.9.5375

Majmundar AJ, Wong WJ, and Simon MC. 2010. Hypoxia-Inducible Factors and the Response to Hypoxic Stress. Molecular Cell 40:294-309. https://doi.org/10.1016/i.molcel.2010.09.022

Murry CE, Jennings RB, and Reimer KA. 1986. Preconditioning with ischemia: a delay of lethal cell injury in ischemic myocardium. Circulation 74:1124-1136. https://doi.org/10.1161/01.CIR.74.5.1124

Nishino T, Okamoto K, Kawaguchi Y, Hori H, Matsumura T, Eger BT, Pai EF, and Nishino T. 2005. Mechanism of the Conversion of Xanthine Dehydrogenase to Xanthine Oxidase: IDENTIFICATION OF THE TWO CYSTEINE DISULFIDE BONDS AND CRYSTAL STRUCTURE OF A NON-CONVERTIBLE RAT LIVER XANTHINE DEHYDROGENASE MUTANT. Journal of Biological Chemistry 280:24888-24894. https://doi.org/10.1074/jbc.M501830200

Przyklenk K, Bauer B, Ovize M, Kloner RA, and Whittaker P. 1993. Regional ischemic 'preconditioning' protects remote virgin myocardium from subsequent sustained coronary occlusion. Circulation 87:893-899. https://doi.org/10.1161/01.CIR.87.3.893

Ritthausen H. 1872. Ueber das Drehungsvermögen von Glutan- und Aepfelsäure. Journal für Praktische Chemie 5:354-355. https://doi.org/10.1002/prac.18720050132

Rzem R, Van Schaftingen E, and Veiga-da-Cunha M. 2006. The gene mutated in 1-2hydroxyglutaric aciduria encodes 1-2-hydroxyglutarate dehydrogenase. Biochimie 88:113-116. https://doi.org/10.1016/j.biochi.2005.06.005

Salvadori M, Rosso G, and Bertoni E. 2015. Update on ischemia-reperfusion injury in kidney transplantation: Pathogenesis and treatment. World Journal of Transplantation 5:52. https://doi.org/10.5500\%2Fwjt.v5.i2.52

Schoenberg M, Fredholm B, Haglund U, Jung H, Sellin D, Younes M, and Schildberg F. 1985. Studies on the oxygen radical mechanism involved in the small intestinal reperfusion damage. Acta Physiologica Scandinavica 124:581-589. https://doi.org/10.1111/j.17481716.1985.tb00051.x 
744

745

746

747

748

749

750

751

752

753

754

755

756

757

758

759

760

761

762

763

764

765

766

767

768

769

770

771

772

773

774

775

776

777

778

779

780

781

782

783

784

785

786

787

788

789
Shen SQ, Zhang Y, Xiang JJ, and Xiong CL. 2007. Protective effect of curcumin against liver warm ischemia/reperfusion injury in rat model is associated with regulation of heat shock protein and antioxidant enzymes. World J Gastroenterol 13:1953-1961. https://doi.org/10.3748/wjg.v13.i13.1953

Susuki S, Toledo-Pereyra LH, Rodriguez FJ, and Cejalvo D. 1993. NEUTROPHIL INFILTRATION AS AN IMPORTANT FACTOR IN LIVER ISCHEMIA AND REPERFUSION INJURY. Transplantation 55:1265-1272. https://doi.org/10.1097/00007890-199306000-00011

Torres-González L, Cienfuegos-Pecina E, Perales-Quintana MM, Alarcon-Galvan G, MuñozEspinosa LE, Pérez-Rodríguez E, and Cordero-Pérez P. 2018. Nephroprotective Effect of Sonchus oleraceus Extract against Kidney Injury Induced by Ischemia-Reperfusion in Wistar Rats. Oxidative Medicine and Cellular Longevity 2018. https://doi.org/10.1155/2018/9572803

Vogler M, Zieseniss A, Hesse AR, Levent E, Tiburcy M, Heinze E, Burzlaff N, Schley G, Eckardt KU, Willam C, and Katschinski DM. 2015. Pre- and post-conditional inhibition of prolyl-4-hydroxylase domain enzymes protects the heart from an ischemic insult. Pflügers Archiv - European Journal of Physiology 467:2141-2149. https://doi.org/10.1007/s00424-014-1667-z

Wang T, Chen H, Lv K, Ji G, Liang F, Zhang Y, Wang Y, Liu X, Cao H, Kan G, Xiong J, Li Y, and $\mathrm{Qu}$ L. 2017. Activation of HIF-1 $\alpha$ and its downstream targets in rat hippocampus after long-term simulated microgravity exposure. Biochemical and Biophysical Research Communications 485:591-597. https://doi.org/10.1016/j.bbrc.2016.12.078

Yildiz F, Coban S, Terzi A, Aksoy N, and Bitiren M. 2015. Protective Effect of Micronized Purified Flavonoid Fraction on Ischemia/Reperfusion Injury of Rat Liver.

Transplantation Proceedings 47:1507-1510. https://doi.org/10.1016/j.transproceed.2015.04.062

Zapata-Chavira H, Hernandez-Guedea M, Jimenez-Perez JC, Perez-Rodriguez E, MunozEspinosa L, Munoz-Maldonado G, and Cordero-Perez P. 2017. Modulation of Remote Ischemic Preconditioning by Proinflammatory Cytokines in Renal Transplant Recipients. Journal of Investigative Surgery:1-9. https://doi.org/10.1080/08941939.2017.1375052

Zapata-Chavira HA, Cordero-Perez P, Casillas-Ramirez A, Escobedo-Villarreal MM, PerezRodriguez E, Torres-Gonzalez L, Camara-Lemarroy C, Hernandez-Guedea MA, Caballero-Mendoza E, and Munoz-Espinosa LE. 2015. Is Ischemic Preconditioning a Useful Therapeutic Strategy in Liver Transplantation? Results from the First Pilot Study in Mexico. Archives of Medical Research 46:296-302. https://doi.org/10.1016/j.arcmed.2015.06.002

Zhang X, Liu Z, Xiao Q, Zeng C, Lai C-H, Fan X, Ye Q, Wang Y, and Xiong Y. 2018. Donor Treatment With a Hypoxia-Inducible Factor-1 Agonist Prevents Donation After Cardiac

Peer] reviewing PDF | (2021:05:61367:2:0:NEW 9 Oct 2021) 
Death Liver Graft Injury in a Rat Isolated Perfusion Model. Artificial Organs 42:280-

289. https://doi.org/doi.org/10.1111/aor.13005 


\section{Figure 1}

Effect of the administration of sodium (S)-2-hydroxyglutarate on the biochemical markers.

a) Effect on the serum activity of ALP; b) effect on the serum activity of $A L T, * p<0.0001$ vs

$\mathrm{SH}$ group, $\# p=0.0002$ vs IR group; $c$ ) effect on the serum activity of AST, ${ }^{*} p<0.0001 \mathrm{vs} \mathrm{SH}$ group, $\# p=0.0465$ vs IR group; d) effect on the serum concentration of glucose, $* p=$ 0.0032 vs SH group, $\neq p=0.0012$ vs SH group; e) effect on the serum activity of LDH, ${ }^{*} p<$ 0.0001 vs SH group, $\# p=0.0109$ vs IR group; f) effect on the serum concentration of total bilirubin. One-way ANOVA test with Tukey post hoc test in a - e; Kruskal-Wallis test with Dunn post hoc test in $\mathrm{f}$. ALP = alkaline phosphatase; ALT = alanine aminotransferase; $\mathrm{AST}=$ aspartate aminotransferase; $\mathrm{LDH}=$ lactate dehydrogenase. Values expressed as mean \pm standard deviation. 

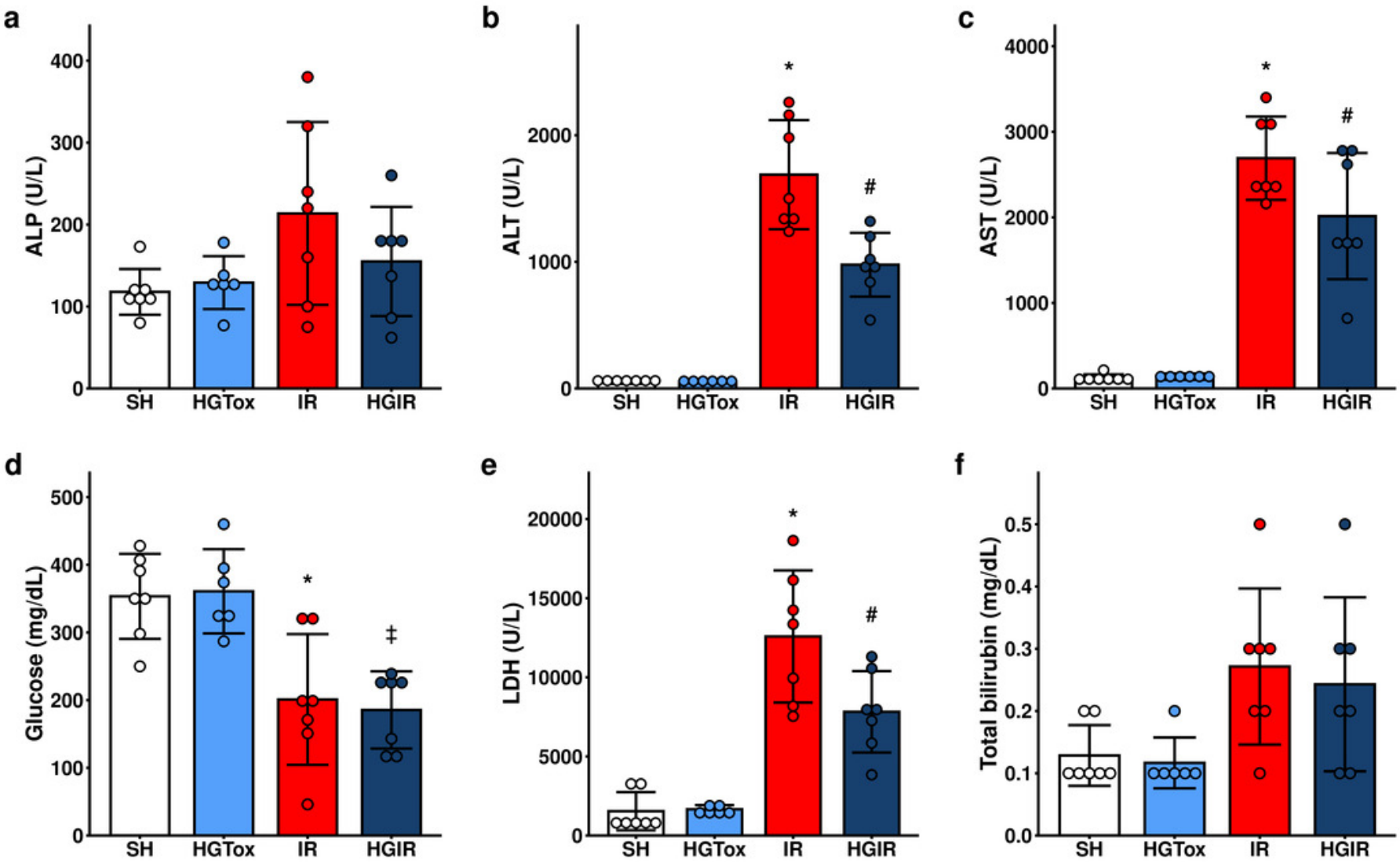


\section{Figure 2}

Effect of the administration of sodium (S)-2-hydroxyglutarate on the proinflammatory cytokines.

a) Effect on the tissue concentration of IL-1 $\beta, * p=0.0228$ vs SH group, $\# p=0.0336$ vs IR group; b) effect on the tissue concentration of IL- $6, \# p=0.0054$ vs IR group, $\neq p=0.0002$ vs $\mathrm{SH}$ group; c) effect on the tissue concentration of TNF, $\neq p=0.0050$ vs SH group. One-way ANOVA test with Tukey post hoc test. IL-1 $\beta=$ interleukin $1 \beta$; IL-6 = interleukin 6 ; TNF = tumor necrosis factor. Values expressed as mean \pm standard deviation.
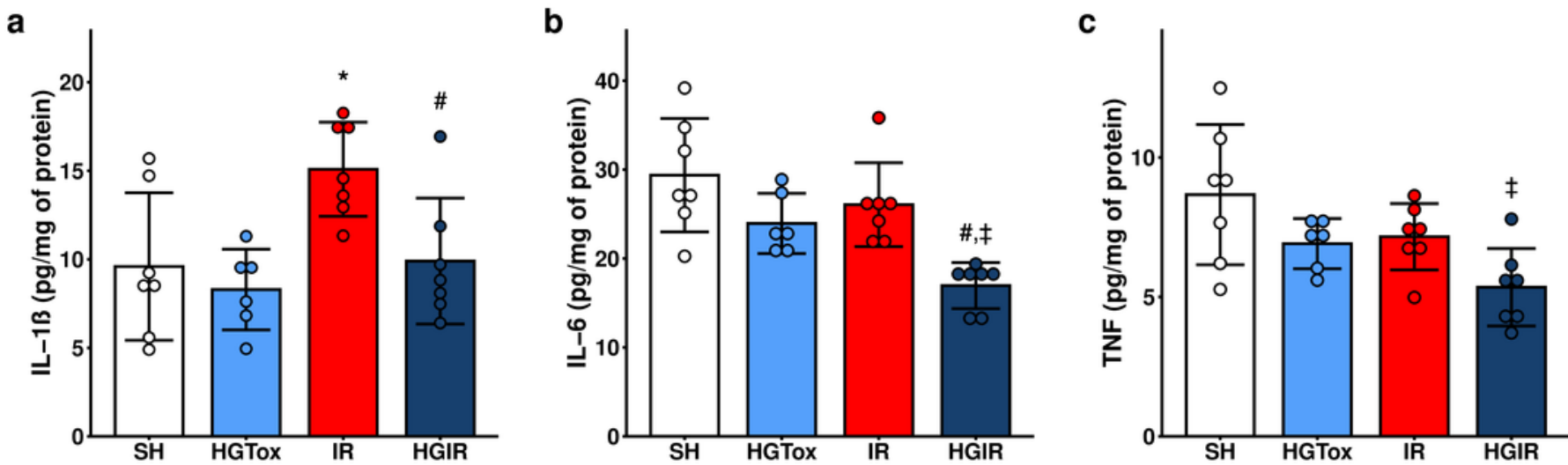


\section{Figure 3}

Representative liver micrographs of the experimental groups.

Hematoxylin and eosin staining (original magnification: 400x). a) SH group, b) HGTox group.

Tissue architecture was conserved in a and $b$, without significant cell necrosis or sinusoidal congestion. c) IR group, d) HGIR group. Severe cellular necrosis is observed in zone 3 of the liver acinus in c, while the severity of the damage was decreased in $d$.
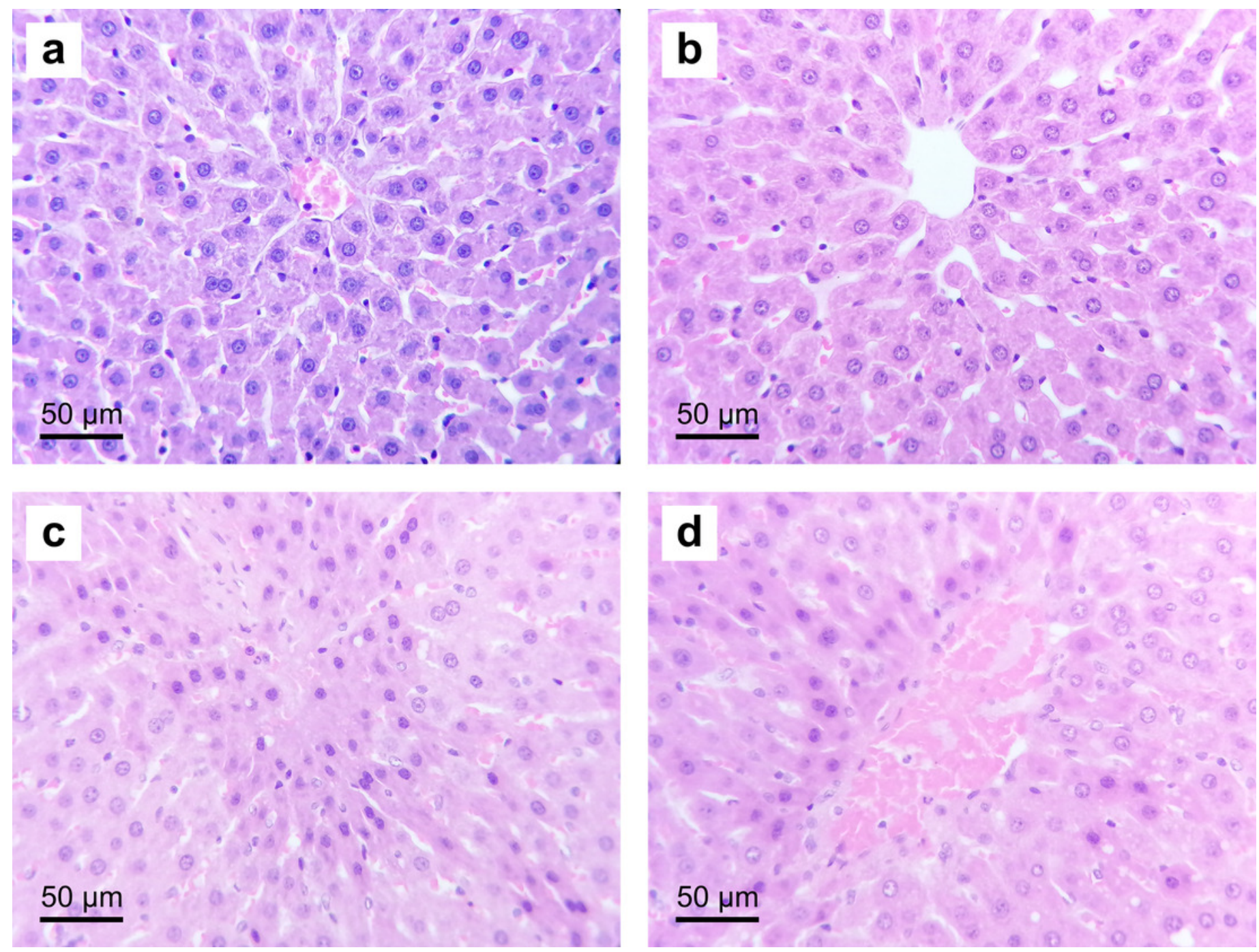
Figure 4

Effect of the administration of sodium (S)-2-hydroxyglutarate on the expression of genes regulated by the HIF-1 pathway in liver tissue.

a) Effect on the tissue expression of $H \operatorname{mox} 1$; b) effect on the tissue expression of Vegfa, $\uparrow p=$ 0.0185 vs SH group; c) effect on the tissue expression of $P d k 1,+p=0.0227$ vs SH group, $* p$ $=0.0204$ vs SH group. One-way ANOVA test with Tukey post hoc test. Values expressed as mean \pm standard deviation.
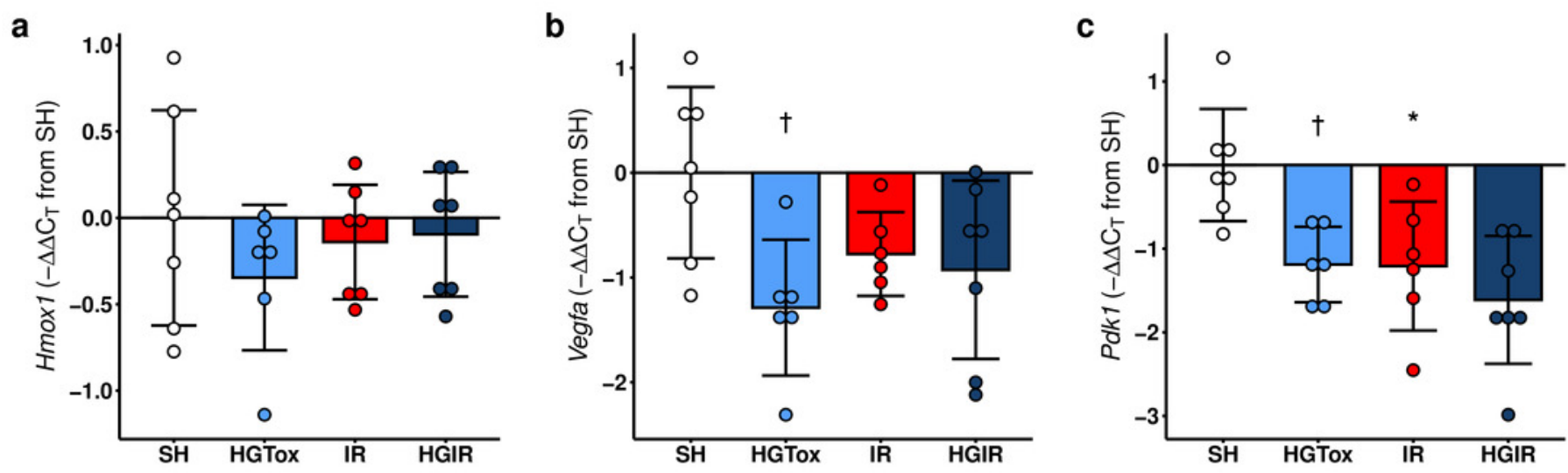


\section{Table $\mathbf{1}$ (on next page)}

Effect of the administration of sodium (S)-2-hydroxyglutarate on the oxidative stress biomarkers.

One-way ANOVA test, Tukey post hoc test. MDA = malondialdehyde; $\mathrm{SOD}=$ superoxide dismutase; GPx $=$ glutathione peroxidase. ${ }^{*} p=0.0304$ vs SH group. 
1 Table 1: Effect of the administration of sodium $(S)$-2-hydroxyglutarate on the oxidative stress

2 biomarkers.

\begin{tabular}{lcccc}
\hline Biomarker & SH & HGTox & IR & HGIR \\
\hline $\begin{array}{l}\text { MDA (nmol/mg of } \\
\text { protein) }\end{array}$ & $651.8 \pm 89.8$ & $745.5 \pm 102.8$ & $594.8 \pm 46.6$ & $615.7 \pm 61.8$ \\
$\begin{array}{l}\text { SOD (IU/mg of } \\
\text { protein) }\end{array}$ & $23.19 \pm 3.15$ & $27.94 \pm 7.33$ & $26.28 \pm 4.98$ & $24.58 \pm 9.53$ \\
$\begin{array}{l}\text { GPx (nmol/min } / \mathrm{mg} \\
\text { of protein) }\end{array}$ & $831.0 \pm 91.3$ & $840.2 \pm 95.4$ & $783.3 \pm 32.6$ & $722.9 \pm 44.2^{*}$ \\
$\begin{array}{l}\text { One-way ANOVA test, Tukey post hoc test. MDA = malondialdehyde; SOD = superoxide dismutase; GPx = glutathione } \\
\text { peroxidase. }{ }^{*} p=0.0304 \text { vs SH group. }\end{array}$
\end{tabular}




\section{Table 2 (on next page)}

Histological evaluation after administration of sodium (S)-2-hydroxyglutarate.

Kruskal-Wallis test, Dunn post hoc test. ${ }^{*} p=0.0002$ vs SH group; ${ }^{* *} p=0021$ vs SH group. The whole dataset is shown in the table. 
1 Table 2: Histological evaluation after administration of sodium $(S)$-2-hydroxyglutarate.

\begin{tabular}{|c|c|c|c|c|}
\hline Parameter & $\mathrm{SH}$ & HGTox & IR & HGIR \\
\hline \multirow{7}{*}{ Cell necrosis } & 0 & 1 & 3 & 3 \\
\hline & 0 & 1 & 2 & 3 \\
\hline & 0 & 0 & 3 & 1 \\
\hline & 0 & 0 & 3 & 3 \\
\hline & 0 & 1 & 3 & 2 \\
\hline & 0 & 2 & 3 & 1 \\
\hline & 0 & ND & 3 & 2 \\
\hline $\begin{array}{l}\text { Median } \\
\text { (Interquartile } \\
\text { range) }\end{array}$ & $0.00(0.00-0.00)$ & $1.00(0.25-1.00)$ & $\begin{array}{c}3.00(3.00- \\
3.00)^{*}\end{array}$ & $2.00(1.50-3.00)$ \\
\hline \multirow{7}{*}{$\begin{array}{l}\text { Sinusoidal } \\
\text { congestion }\end{array}$} & 1 & 1 & 3 & 1 \\
\hline & 2 & 2 & 3 & 2 \\
\hline & 1 & 0 & 2 & 2 \\
\hline & 0 & 1 & 2 & 2 \\
\hline & 0 & 2 & 3 & 2 \\
\hline & 0 & 0 & 3 & 1 \\
\hline & 1 & ND & 3 & 0 \\
\hline $\begin{array}{l}\text { Median } \\
\text { (Interquartile } \\
\text { range) }\end{array}$ & $1.00(0.00-1.00)$ & $1.00(0.25-1.75)$ & $\begin{array}{c}3.00(2.50- \\
3.00)^{* *}\end{array}$ & $2.00(1.00-2.00)$ \\
\hline \multirow{7}{*}{$\begin{array}{l}\text { Cytoplasmic } \\
\text { vacuolization }\end{array}$} & 0 & 0 & 0 & 1 \\
\hline & 0 & 0 & 1 & 1 \\
\hline & 0 & 0 & 0 & 0 \\
\hline & 0 & 1 & 0 & 0 \\
\hline & 0 & 1 & 1 & 2 \\
\hline & 0 & 0 & 3 & 1 \\
\hline & 0 & ND & 0 & 0 \\
\hline $\begin{array}{l}\text { Median } \\
\text { (Interquartile } \\
\text { range) }\end{array}$ & $0.00(0.00-0.00)$ & $0.00(0.00-0.75)$ & $0.00(0.00-1.00)$ & $1.00(0.00-1.00)$ \\
\hline
\end{tabular}

